\title{
An investigation into the uniformity and non-uniformity of online/offline retail brand building in South Africa
}

\author{
H. Kruger* \\ Graduate School of Business, University of Stellenbosch \\ PO Box 610, Bellville 7535, Republic of South Africa \\ hpienaar@usb.sun.ac.za \\ L.C.H. Fourie \\ Graduate School of Business, University of Stellenbosch, \\ PO Box 610, Bellville 7535, Republic of South Africa \\ lchf@usb.sun.ac.za
}

Received October 2003

\begin{abstract}
Brand equity or -value is the result of the design and implementation of brand building, - measurement and management programs. Brand building focuses on three interdependent tiers: selecting brand elements, choosing certain marketing activities and programs, and linking the brand to secondary brand associations. A brand holder's first instinct may be, when it decides to evolve to the Internet, to maintain the status quo of its offline brand equity or value, by building a uniform online/offline brand. However, from the literature it is evident that authors are not united in their support of building uniform online/offline brands. Although building a uniform online/offline brand present certain tangible advantages, uniformity or non-uniformity proves not to be a binary decision, but dependant on the strategic imperative of the three tiered online/offline brand building initiative. To research three tiered online/offline brand building from a South African perspective, the uniformity and non-uniformity of brand name selection within the South African online/offline retail environment is firstly investigated. The advantages of building uniform online/offline brands are secondly elucidated as presented by the marketing programs - and activities of selected South African retail brands. Secondary brand associations, as part of the three tiered brand building phase or as separate strategic imperative, and the role it plays in non-uniform online/offline brand building, is thirdly examined. Findings are summarised, conclusions are drawn that elucidate the uniform and non-uniform brand building strategies of South African online/offline retailers and recommendations are made for future research.
\end{abstract}

*To whom all correspondence should be addressed.

\section{Introduction}

\section{Brand building}

Aaker (1991: 7; 17) defines a brand as '.... distinguishing name and/or symbol (such as a logo, trademark, or package design) intended to identify the goods or services of either one seller or a group of sellers, and to differentiate those goods or services form those of competitors.' He proceeds to explain that brand equity $(1991: 15)$ is the '... set of brand assets and liabilities linked to a brand, its name and symbol, that add to or subtract from the value provided by a product or service to a firm and/or that firm's customers'. According to Interbrand (Clifton \& Maughan, 2000: viii) a brand is '... an intangible asset that creates an identifiable economic earnings stream'. The value of the brand is further defined as '...the net present value of the economic profit that the brand is expected to generate in future'.

Keller (2003) expands on the equity concept, redefining it as a strategic brand management process designed to create customer-based brand equity. Customer-based brand equity is created in four stages. Brand positioning and values are identified and established in the first stage. In the second stage, the brand marketing programs are planned and implemented. The brand's performance are qualitatively and quantitatively measured and interpreted in the third stage. In the fourth stage, strategies concerning the growth and maintenance of the brand's equity, for example brand extension and - revitalisation, are executed.

Building the brand (compare stage two of Keller's (2003) strategic brand management process) consists of three tiers: selecting brand elements, developing marketing activities and - programs, and leveraging secondary brand associations. The brand elements are a configuration that consists of the brand name, logo, symbol, character, packaging, and slogan. Marketing activities and - programs pertain to the product itself and the price at which it will be sold, the place where it will be sold and the promotions that will be used to do so. Secondary associations involve linking the brand to another entity, for example another brand, to reinforce the brand and build brand equity.

Assuming that the positioning and values of the brand have been identified and established, it should thus be evident 
that brand equity can not be created if all three tiers of the brand building phase are not clearly, consistently and coherently designed and executed. The brand elements must be supported and strengthened by the marketing programs and - activities as well as the secondary associations. A brand element, for example the brand name, does not by itself contribute to the creation of brand equity. It is only when the brand name, as part of a three tiered strategic brand building strategy, acts to identify or differentiate its multi-dimensional entity called the brand and they become one entity, that both become noteworthy in the creation of brand equity.

In order to maintain and possibly increase the value of the brand, an organisation may decide to maintain the status quo of its offline brand by specifically keeping its brand uniform for both the online and offline environments. The implication of the aforementioned strategy is that the offline brand name, also referred to as the bricks-and-mortar brand name, and the online brand name, also referred to as the bricks-and-clicks brand name, remain identical, and is not dependent on or defined by the nature of the environment be it physical (bricks-and-mortar/offline) or virtual (bricksand-clicks/online). The former also subsumes that the marketing programs and - activities as well as secondary associations of the online brand will be largely uniform when compared to the offline brand. The presumption is that the brand equity attached to the brand name, will be transferable to the new virtual environment, where it will function (as in the physical environment) to create valuable brand equity for the organisation. As this paper intends to illustrate, a uniform online/offline brand building strategy is neither the only, nor necessarily the most advantageous choice.

\section{Background}

Authors are not united on the subject of keeping an online/offline brand name uniform when venturing into cyberspace (Kania, 2000: 128).

European brand strategy experts on the one hand, when confronted with the question whether an organisation should build a new brand for the Internet or use the existing brand, expressed the sentiment that '...European consumers prefer to see familiar brands online' (Business Europe, 2000). Lindström (2001: 367) explained the Europeans' affinity for brand uniformity in the physical and virtual environment: most offline brands have already earned and built the consumer's trust over years, and therefore the consumer will welcome online interaction with such a brand. He also advised online brands to maintain their offline relationships with consumers if they venture and want to prosper online. The sentiment was thus to keep the brand name uniform in the online/offline environment.

According to Carpenter (2000: 12) the crossover marketers (organisations created in and for the traditional offline environment that subsequently evolved to the online environment) did so successfully because certain best practices were developed. The best practises included: maintaining consistency and clarity between the core offline and online brand elements; improving online on the offline brand experience; and leveraging the offline brand assets to build brand awareness for the online brand. However, the aforementioned best practices of crossover marketers only became applicable if the brand name was uniform in both the physical and virtual environment.

Aaker on the other hand, as quoted by Greene (1998), stated that 'You can damage your brand if you stretch it too far' when attempting to inflate an offline brand to the online environment with a uniform character. O'Keefe (2000) also warned that it can become difficult to deliver on the brand promise as the brand evolves to and in the online environment.

However, Gulati and Garino (2000) advised that the decision to build a uniform online/offline brand (they refer to brand integration) when moving online, in contrast to selecting a non-uniform brand (they refer to brand separation) for the online venture, was not a mutually exclusive either/or decision. The authors suggested that an online brand could be a new entity which was for example the result of partial integration with its own offline brand or an alliance between its own offline brand and another online/offline brand, and was therefore neither uniform nor non-uniform. If brand integration (uniformity) was at one extreme of a spectrum and brand separation (nonuniformity) at the other end, online brands could be transformed to fall on or between the two extremities, depending on the strategic intent of the online brand holder.

\section{Aim and structure of the paper}

The primary aim of the paper is to investigate the uniformity and non-uniformity of online brand building strategies of South African retailers with an existing offline brand. To realise this primary aim in the first instance, a macro profile of online/offline retail brand name uniformity and nonuniformity, which relate to the first tier of the brand building phase, will be compiled. Secondly, the advantages of online/offline brand building uniformity practises as identified by Carpenter (2000), which relate to the second and third tier of the brand building phase, will be critically applied to selected examples of uniform online/offline retail brands in South Africa. Thirdly, the integration/separation complexity spectrum debated by Gulati and Garino (2000), which relate to the third tier of the brand building phase, will be explained and the motivation and merits of each permutation upon the spectrum will be briefly highlighted, using South African online/offline retail brands to do so. The paper will in the fourth and final instance, summarise the most important observations of the research; come to a conclusion based on the summary, and make recommendations deducted from the conclusion.

\section{Macro profile of online/offline retail brand name uniformity and non-uniformity in South Africa}

\section{Research methodology}

A South African database of offline brand names and their online compeers is required to draw a macro profile of online/offline retail brand name uniformity and nonuniformity in South Africa. However, since such a database 
did not exist, it had to be constructed before proceeding with the profile assemblage. The database was constructed in two stages. In the first stage, definitions of retail trade, retailer, and online retail, as well as product categorisations of South African online retailers, were examined to define the population to be researched. In the second stage, the web site of each online retailer was examined with the use of fourteen parameters and the resultant observations recorded. The macro profile of online/offline retail brand name uniformity and non-uniformity in South Africa was assembled after the observations were analysed.

\section{Defining the research population}

Arthur Goldstuck published the central findings of an annual survey, entitled 'The Goldstuck Report: Online Retail in South Africa, 2002' on retail e-commerce in South Africa. He accepts the definitions of Statistics South Africa of retail trade, retailer and online retail. Retail trade is defined as 'The resale (sale without transformation) of new and used goods and products to individuals/the general public for household use' and retailer as '....an enterprise deriving more than $50 \%$ of its turnover form sales of goods to individuals/the general public [traditionally bought through physical retail trade] for household use'. Online retail is described as '... retail sales conducted or facilitated via the Internet, usually on a web site, but may include the use of email as a mechanism for any or all of the following: negotiation, confirmation, authorisation and conclusion of a sale' (Goldstuck, 2002: 5-8). Goldstuck used a narrow definition of business-to-consumer retailers (WorthingtonSmith, 2002: 138-140) when he examined online retailers. Property, cars, travel and financial services were excluded from the examination as overall e-commerce that includes these categories are 20 to 40 times the size of online retail excluding these categories, resulting in a distortion of the statistical picture of online retail.

For the purposes of this paper it was decided to accept the above definitions and use it to determine the population from which the database of online retail brand names and associated brand building strategies could be built.

According to Goldstuck (2002: 3), the number of online retail websites increased from 72 (112 websites at the end of 2000 minus 40 websites that became inactive during 2001) at the end of 2001, to 215 at the end of 2002 . The 215 online retailers, which remained at the end of 2002, were divided into 17 categories accompanied by their web site addresses and online retail names. The 17 categories are depicted in Table 1 below

\section{Table 1: Retail categories}

\begin{tabular}{ll|l}
\hline 1. & Adult & 10. Music \\
2. Health and beauty & 11. Electronics \\
3. Apparel & 12. Sports and recreation \\
4. Home and garden & 13. Flowers and gifts \\
5. Appliances & 14. Toys and hobbies \\
6. Jewellery & 15. Food and beverage \\
7. Arts, crafts and collectables & 16. Wine \\
8. Lingerie & 17. General \\
9. & Books, magazines and stationary & \\
\hline
\end{tabular}

Source: Goldstuck, 2002.
For the purposes of this paper it was decided to accept the above online retail categorisation and use it for the stratification of the population, from which the database of online retail brand names and associate brand building strategies could be constructed.

However, only 16 of the 17 categories were researched in order to compile the profile. The adult online retail category was excluded due to ethical reasons. The size of the online retail population of 211 (215 minus four adult online retailers) was considered to be large enough to compile a meaningful and significant profile from the population, without examining the adult online retailers.

\section{Parameters of online retail web sites}

The web site of each online retailer was examined using a framework that consisted of the following 14 fields:

1. The number of hits the online brand name generated on a specific date using the Google search engine.

2. The offline brand name of the online retailer: known, unknown or not applicable.

3. The number of hits the offline brand name generated on a specific date using the Google search engine.

4. The web site address (URL): accessible or inaccessible.

5. The e-mail address: existent or non-existent.

6. The e-mail address: accessible, inaccessible or unknown.

7. Questionnaire via e-mail: yes, no, or not applicable.

8. The offline brand and brand name: existent, nonexistent or unknown.

9. The uniformity of online and offline retail brand names: yes, no, unknown, or not applicable.

10. Partnerships with online brands: yes, no, unknown, or not applicable.

11. Partnerships with offline brands: yes, no, unknown, or not applicable.

12. Distributor for offline brand: yes, no, unknown, or not applicable.

13. The online brand is an extension of the offline brand: yes, no, unknown, or not applicable.

14. The online and offline brands and brand names are linked: yes, no, unknown, or not applicable.

The results of each field (except one and three, that were quantitative observations) for every separate category was aggregated and expressed as a proportion of the category. This resulted in 12 proportions per category. The end result 
included 192 proportions (12 proportions multiplied by 16 categories). Because these proportions only elucidated proportional differences in certain fields between certain categories, all the observations of the 16 categories within a specific field were aggregated and expressed as a proportion of the total online retail population. This was done in order to create a profile, which could be used to reflect for example, brand name uniformity of the total online retail population, as was stated in the aim of this paper.

\section{The profile}

Online brand name uniformity and non-uniformity can be elucidated by examining the proportional expression of uniform and non-uniform online/offline brand names. An online brand name is uniform if it is identical to the offline brand name. If it is not identical, it is referred to as nonuniform. The uniformity or non-uniformity of a brand name can therefore only be considered and judged if an offline brand and brand name exist. To assemble the profile of online brand name uniformity, the proportion of online brand names without an existing offline brand name first had to be determined to be subsequently eliminated.

\section{The existence of an offline brand}

If an offline brand name existed, a 'yes' answer was recorded and subsequently if not, a 'no' answer. A 'not applicable' answer was recorded if the universal resource locator (URL) could not be retrieved after three attempts. An 'unknown' answer was recorded if it could not be determined from the web site if an offline brand name existed and the online retailer could not be contacted via email (for example the email address was not functional or not available), or was contacted via e-mail but chose not respond.

The 'yes'/'no'/'not applicable'/'unknown' observations of all the categories that refer to the existence of an offline brand name were aggregated and then expressed as a proportion of the total (211) online retail population. The results are expressed in figure 1 below.

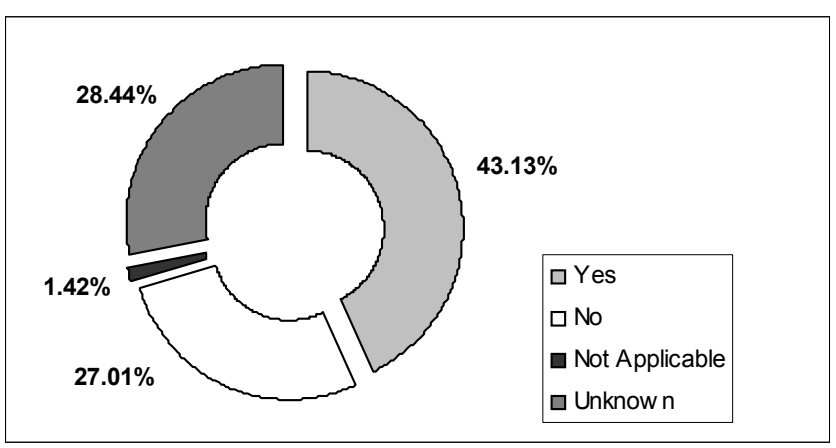

Figure 1: Offline brand name existence

From figure 1 it is evident that a significant proportion of the online retail population $(43.1 \%)$ do have an offline brand name and only a very small proportion (1.4\%) was either inactive or temporarily not available. This may be an indication of less online failures despite the economically difficult time.

\section{The uniformity of the online brand}

If an offline brand name existed and the offline and online brand and brand names were uniform, a 'yes' answer was recorded and subsequently if not, a 'no' answer.

The 'yes'/'no' observations of all the categories that refer to the uniformity of the offline and online brands names were aggregated and then expressed as a proportion of the total (211) online retail population. The results are expressed in Figure 2 below.

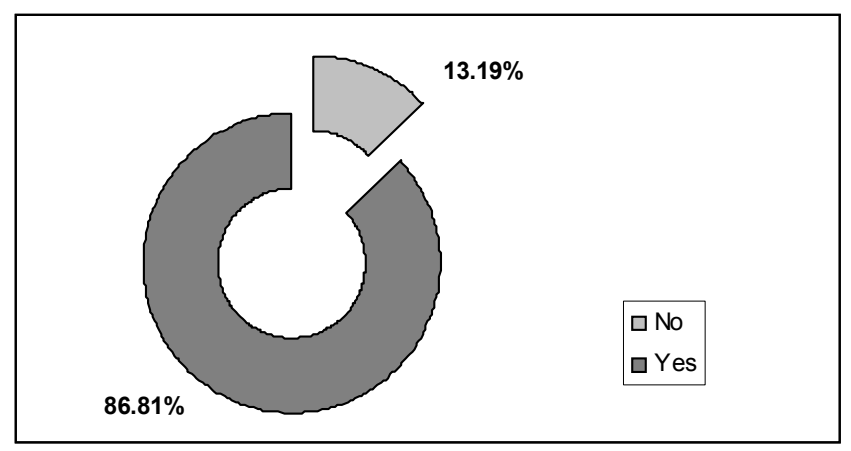

Figure 2: Online brand name uniformity

Figure 2 illustrates that the proportion of brand name uniformity within the South African online retail population, given that an offline brand exists, is surprisingly large at 86,8 percent.

This may be attributed to the fact that the majority of offline retailers kept their brands names uniform when they entered the virtual environment. This group includes both relatively well known offline retailers such as Edgars, Exclusive Books, Interflora, Pick ' $\mathrm{n}$ Pay, M-Web, Giddys, Musica, Reggies and Nederburg Wines, as well as relatively unknown offline retailers such as Jamboree Kids Clothing, Phonemac, Central Liquors, Austware and Diamonds for Africa.

The proportion of non-uniform brand names within the South African online retail population, given that an offline brand exists, is comparatively small at 13,2 percent. The small minority of offline retailers that have chosen nonuniform brand names for the virtual environment includes both relatively well known offline retailers such as Woolworths and Naspers, as well as relatively unknown offline retailers such as The Winchester Foundation and Sample Division.

It seems as if the proportion of online retailers within South Africa that have kept their brands names uniform, are disproportionately large when compared to the online retailers who have chosen a non-uniform brand name for the virtual environment. The major advantage of uniformity and primary motivation in favour of a uniform online/offline brand name initiative is that it is by implication also 
supported by a uniform existing offline brand building strategy (transferable to the online environment) that includes the marketing programs and - activities as well as secondary associations.

\section{Advantages of uniform online brand building practices}

The advantage (which probably explains the large proportion of online/offline retail brand name uniformity in South Africa) of a uniform online/offline brand building strategy is threefold.

The brand equity of the existing offline brand, can be extended to build the online brand (Aaker \& Joachimsthaler, 2000: 234; Carpenter, 2000: 131; Clifton \& Maughan, 2000; Kania, 2000: 128, 130, 131; O'Keefe, 2000; Timacheff \& Rand, 2001: 83) as it orchestrates consistency between and clarity of the online/offline core brand attributes. The Pro Shop, a South African offline retailer (category sports \& recreation) specialising in golf paraphernalia, kept its brand name uniform when it moved online. The existing strong offline core brand attribute (the Pro Shop of all pro shops) were extended to the online brand. This resulted in a consistent and clear representation of the brand across offline and online markets, strengthening the brand name in general and building the brand in particular.

The online brand has the potential to improve online on the experience of the offline brand (Aaker \& Joachimsthaler, 2000: 242), as '.. the digital medium gives customers different expectations of brands' (Kania, 2000: 45; Hockin, 2002: 17). This should result in what Carpenter (2000: 133) calls an incremental customer experience (also see McNaughton, 2001) and superior customer service that result in brand fortification. For the brand to be fortified it is a prerequisite that the online brand should not narrow the offline brand by only being an explanation of the latter's products (Lindström \& Andersen, 2000: 187; Greene, 1998); it should result in the generation of additional brand value. Exclusive Books, a South African retailer (category books, magazines \& stationary), is an example of an offline brand that extended its offline brand online and used the virtual environment to aggregate and compound the customers' experiences. Added functionality generates additional value that fortifies the brand through incremental customer experiences which can be measured according to the increase in brand equity.

The value (in the form of brand loyalty) of the offline brand can be leveraged to create direct value (in the form of brand awareness) for the online brand, and indirect value (in the form of reduced marketing expenditure) for the brand holder (Carpenter, 2000: 13). Braunstein and Levine (2000: 229) illustrated this advantage by stating that an organisation with a multi-channel business already had created many 'richer points-of-contact with the buyer' and therefore understood the customer far better than an organisation with a single channel business (also see Kania, 2000: 31). An example of this advantage would be the utilisation of an existing offline promotional infrastructure to create awareness for the online brand, transforming awareness to brand preference that evolves into brand loyalty. This is confirmed by Kania
(2000: 133,123). Pick and Pay is a South African offline retailer (category food \& beverages) that entered the online environment with a uniform brand, called Pick and Pay Home Shopping. The physical infrastructure of the existing bricks-and-mortar stores is leveraged to fulfil online ordering requirements. The website address (URL) of the online brand appears in traditional media promotions, on product packaging, on delivery trucks and as a link from other websites. The offline brand assets, if leveraged strategically (and uniformly to support the online brand name) as in the above example, will build both the online and offline brand.

The advantages of building a uniform brand for physical and virtual markets, as well as the high occurrence thereof in the South African retail market, seem reason enough for a retailer to justify keeping its brand uniform irrespective of the nature of the market. The decision, however, to keep the brand uniform may not always be the only and most advantageous decision, especially if circumstances proof to be more complex than it seemed on the surface and with the first impression.

In order to understand the true nature of brand uniformity and make certain observations that pertain to the South African online retail environment, it is necessary to look at the area (complexity spectrum) between the opposites brand uniformity and non-uniformity and the permutations that occupy this area, as well as the motivations and merits of specific permutations on the complexity spectrum.

\section{Complexity spectrum}

The perception may exist that online brand uniformity and non-uniformity are the only choices available to an offline retailer. However, strategic considerations may result in a customised online brand being built, that is neither uniform nor non-uniform. Brand uniformity and non-uniformity as well as each permutation (spin-off; joint venture; partnership) between the two extremities, will be briefly discussed. Examples of the brand building initiatives of South African online retailers will be briefly applied to the discussion of each permutation. The relative advantages of each permutation and the influence it has on the third tier of the online brand building process will be elucidated.

An offline retailer, expanding to the online environment, may decide in the first instance, to keep the online and offline brand uniform. The motivation behind this decision would be the possibility to improve the customer experience through cross-selling opportunities. This decision can be successfully implemented if the physical and virtual retail outlets are integrated to create a 'single, seamless retailing network' (Gulati \& Garino, 2000). Pick 'n Pay Home Shopping is an example of a uniform online/offline brand that is in the process of creating such a single, seamless retailing network. The resultant brand consistency and the leverage of the offline brand assets to create and build the online brand, merit a retailer's commitment to this initiative.

The uniform South African online retail brands may be divided into two groups. The first group include the better known national offline retailers such as Edgars, and the 
second group include the lesser known or relatively unknown retailers such as Foxy Fashions.

Offline retailers such as Edgars, Truworths, Stuttafords and Reggies have an existing strong offline brand and established brand equity, but seem not to have utilised both the Internet and the brand equity of the offline brand. Even though the online/offline brands are uniform, cross-selling opportunities that will improve the customer experience are non existent and offline brand assets are not leveraged to build the online brand. In this instance, a strategy of uniform online/offline brand building is difficult to motivate, as none of the reasons (for example the possibility to leverage offline brand assets) for building a uniform online/offline brand are detectable. This may lead to the supposition that the uniform online/offline brand building initiative was not the result of a strategic imperative.

Most of the uniform online brands that have been examined that fall into the second group may, and should, be described as 'identities'. This expression is used by Braunstein and Levine (2000: 71) to describe an online presence that have very limited brand awareness, and consequently do not enjoy any of the advantages of brands with strong brand equity. It may therefore seem unfair to evaluate the online/offline brand building initiatives of these 'identities', but for illustrational purposes it was decided to do so.

The above 'identies' include Foxy Fashions (an offline retailer with two physical outlets); Artika Ceramics (an offline brand that has decided to move online to broaden its presence); Phonemac (an offline retailer offering a limited product range online); Central Liquors (an online brand that functions as distributor and infomediary for the offline brand); Motalibs (an offline butcher specialising in catering for a specific geographical area that uses its online presence for order fulfilment); Multibraai Online (online catalogue with no e-commerce facilities), and Diamonds for Africa (tenders for the international market with online presence functioning as additional sales channel with limited merchandise).

Online retail identities that fall into this second group do not offer cross selling opportunities and do not leverage offline brand assets to build the online brand. Although a strategy of uniform online/offline brand building is also difficult to motivate in this instance, inadequate or non-existent infrastructure may be justifiable motivation.

An offline retailer, expanding to the online environment, may decide in the second instance, to keep the online and offline brand uniform, but to establish the online brand as a separate division of the organisation. This permutation is mentioned and shortly discussed, even though it could not be determined, which of the South African uniform online retail brands were established as separate divisions of the organisation. In this instance, the online brand is a spin-off of the offline brand, according to Gulati and Garino (2000). The motivation for following this strategy is fourfold. It will firstly increase decision making speed and flexibility, create an entrepreneurial culture secondly, thirdly attract quality management, and fourthly make it easier to obtain venture capital available to internet pioneers. Following this strategy will, however, only be merited if it will be possible for the online brand to leverage the offline brand assets to help build the online brand. The aforementioned limitation is at present only relevant to American companies where nexus laws ${ }^{1}$ prohibit offline retailers to do so under certain conditions, rendering the benefits of building a uniform brand across physical and virtual markets meaningless (Carpenter, 2000: 136). The probability, however, that laws of this nature will become applicable within the South African commercial environment is small as the sizes of the offline organisations are presently not disproportionately large enough to provide its online venture with an unfair advantage compared to its online only competitors.

An offline retailer may decide in the third instance to form a joint venture with another existing online retailer to create a single, 'new', non-uniform online brand which is shared between the different and formerly separate online/offline retailers (Gulati \& Garino, 2000). This strategy is motivated by the opportunity to leverage offline brand assets to build the new online brand, improving on purchasing leverage and supplier exclusivity. A joint venture will only be merited under certain conditions in specific retail categories: where channel conflict is absent and where flexibility is more important than price sensitivity in for example the retail category of toys and hobbies. A South African online retail brand that was researched and may be described as the result of an online and offline joint brand venture is Walrus Clothing (joint venture between Hedgehog Clothing and Bossyboots). Icanonline (a combined financial services and shopping site) is another example of a joint venture between Nedcor (bank) and MWeb (internet service provider).

An offline retailer may fourthly, decide to acquire a share in an existing online retailer to form a partnership (Gulati \& Garino, 2000). In contrast to the joint venture, the offline and online brands in a partnership remain distinct and nonuniform and are promoted separately in the offline and online channels. The offline retailer will be motivated to pursue this strategy if it needs a presence on the internet and does not want to spend the time or make the financial investment in order to do so. An offline retailer will be motivated to form a partnership because the offline brand can be promoted and protected while the advantages of the online brand are optimised. South African retail brands that may be described as the online partner of an existing offline brand is Africa in Gear (offline partner The Jane Goodall Institute); Kalahari.net (offline partner Naspers); The Mindframe Technique (offline partner The Winchester Foundation) and Megashopper (offline partner Spar Group).

An offline retailer may decide in the fifth and final instance to establish a non-uniform online brand that is not connected to the offline brand in any significant manner and does not utilise the brand equity of the offline brand to build the online brand. A retailer may be motivated to pursue this strategy of non-uniformity in order to minimise risk to the offline brand in an uncertain environment and turbulent

\footnotetext{
${ }^{1}$ The nexus laws in the United States of America prevent the utilisation of the offline retailer's brand equity to help built the online brand if the size of the offline organisation is so large and powerful, that it would provide the online venture with an unfair advantage compared to an online only competitor.
} 
economy and/or to accommodate a different online target audience by restructuring the online brand's objectives. The small proportion (13.1 percent) of online retailers in South Africa that have followed this strategy of non-uniformity creates the impression that the strategy may not be merited in practice. However, the small proportion of non-uniform online retail brands (for example Inthebag from Woolworths and eBucks from the First Rand Group) complicates the investigation of the motivation and merits for doing so. The strategy should therefore not summarily be rejected.

Certain offline brands appear to be in online brand limbo. Comfort Shoes On-Line is neither the result of an online/offline retail brand partnership nor a joint venture. Police Sunglasses are distributed via the online retailer The Duchess Optical Group with which it is neither in partnership or joint venture. Carol Boyes Functional Art has a website with no e-commerce facilities that fulfils the function of virtual catalogue and sales channel infomediary while various offline and online brands distribute the products of companies with whom there are no partnership or joint venture agreements. The above may possibly qualify as examples of brand separation.

Gulati and Garino (2000) describe the uniformity or nonuniformity of the online brand in terms of its degree of integration and separation from the offline brand. A uniform online brand is therefore integrated and a non-uniform online brand separated. They point out that integration and separation is not a binary choice and that infinite permutations exist within this spectrum of integration and separation complexity. A spin-off online brand may therefore be considered uniform, but is not necessarily integrated with the offline brand. The online brand that is the result of a joint venture may display different levels of integration and separation when compared to the unique amalgamation of integration and separation levels of a partnership.

\section{Summary, conclusion and recommendations}

\section{Summary}

A brand is a multidimensional concept that creates value for the brand holder that is measurable in pecuniary terms. Brand equity or - value is the result of a four stage process. This paper focused on the second stage of this process, called building the brand which consists of three interdependent tiers. The first tier addressed brand elements, the second tier marketing programs - and activities and the third tier secondary associations. Most brand holders have the perception that their offline brands could and should be transferred in situ (uniformly) to the online environment.

Authors are not united on the subject of building a uniform online/offline brand, arguing on the one hand that consumers want to see familiar offline brands in the unfamiliar online environment, while on the other hand stating that offline brands could be damaged if inflated beyond its potential to the online environment. The advantages of building a uniform online/offline brand seemed however to be convincingly advantageous. It was only when online brand building strategies were suggested which did not conform to either uniform or non-uniform online brand building, that the obvious advantages of online/offline brand uniformity were questioned.

An online/offline brand name uniformity profile of South African online retailers (tier one of the brand building process) indicated a high proportion (86.8\%) of online/offline brand name uniformity. Certain offline brands successfully built a uniform online/offline brand because the marketing programs and - activities (tier two of the brand building process) for the online/offline brand building initiative were strategically linked with the first tier. However, few South African online/offline retailers took the third tier of the brand building process, either as secondary brand associations or as independent online/offline brand building strategy, into consideration. The former was confirmed by the small proportion of joint ventures and partnerships within this population.

\section{Conclusion}

Although the research indicated that a convincingly large proportion of the South African offline retailers built uniform online/offline brands, it could by no means be confirmation that it was the result of an interdependent three tiered brand building strategic imperative and thus be justification of its appropriateness as strategy. Research further indicated that only some of the offline retailers built uniform online/offline brands with strategic imperatives and success, contemplating and executing at least the first two tiers of the three tiered brand building process. However, the success of building a uniform online/offline brand in the former instances may be negated by the existing strength of the offline brand equity. If the third tier of the brand building process is also included either as a secondary association or as a separate online brand building strategy, it should be reflected indirectly in the proportion of nonuniform online brand names. The high proportion of online brand name uniformity, which relates to the first tier, may also possibly explain the insignificantly small proportion of online/offline South African retail brands that also took the third tier of the brand building process into consideration.

\section{Recommendations}

The issue of whether the uniformity of an online/offline brand building strategy in South Africa is and should be dependent or independent of its environment, as well as the extent of dependence or independence still has to be solved in further research.

It would also be of value to investigate if the high proportion of brand name uniformity in South Africa is typical of the retail industry as a whole or if there are correspondingly large and small proportions of brand name uniformity within and between the separate retail categories. The proportions of uniformity, if it exists, should be classified and if variation is present, it should be examined.

Lastly, the circumstances under which and the conditions for building a uniform or non-uniform online/offline brand in South Africa, with specific focus on the third tier of the 
brand building process, should be carefully studied and determined.

\section{References}

Aaker, D. A. 1991. Managing brand equity: Capitalizing on the value of a brand name. New York: The Free Press.

Aaker, D. A. \& Joachimsthaler, E. 2000. Brand leadership. London: Simon \& Shuster.

Business Europe, December 2000, 40(14): 7. Brand management in cyberspace (2).

Braunstein, M. \& Levine, E. H. 2000. Deep branding on the internet: understanding and increasing the impact of the web on your brands, your marketing plans, and your company's destiny. Roseville, California: Prima Communications Incorporated.

Carpenter, P. 2000. eBrands: Building an Internet business at breakneck speed. Boston, Massachusetts: Harvard Business School Press.

Clifton, R. \& Maughan, E. (Ed.). 2000. Twenty-five visions: The future of brands. London: Macmillan Press.

Green, H. 1998. The deadest aim in the branding shootout. Business Week. 28 August: 1-4. [online]. URL: http://www.businessweek.com/@@OyEdslYQDOGB@gsA /1998/36/b3594012 htm. (Accessed 26 March 2003.)

Goldstuck, A. 2002. 'The Goldstuck report: Online retail in South Africa, 2002'. Unpublished research report. Blairgowrie.

Gulati, R. \& Garino, J. 2000. 'Get the right mix of bricks and clicks', Harvard Business Review, 78(3): 107-115.

Hockin, D. 2002. 'How to avoid an identity crises online', Brand Strategy, March, 157: 17.

Keller, K. L. 2003. Strategic brand management: Building, measuring, and managing brand equity. New Jersey: Pearson Education.

Kania, D. 2000. Branding.com: Online branding for marketing success. Chicago: NTC Business Books.

Lindström, M. 2001. 'Corporate brand and the Web: A global/local challenge', Brand Management, 8(4\&5): 365368 .

Lindström, M. \& Andersen, T. 2000. Brand building on the Internet. Dover: Kogan Page Limited.

McNaughton, R. 2001. 'Online branding', New Zeeland Marketing Magazine, 19(11): 15-18.

O'Keefe, K. 2000. 'A word of advice to the Body Shop: Don't underestimate you fine branding with inconsistent internet effort', Brandweek, 41(37): 34-36.
Timacheff, S. \& Rand, D. 2001. From bricks to clicks: Five steps to creating a durable brand. New York: MacGrawHill.

Worthington-Smith, R. (Ed.). 2002. The E-business handbook 2002: The 2002 review of how South African companies are making the Internet work. $3^{\text {rd }}$ Edition. Cape Town: Trialogue.

Worthington-Smith, R. (Ed.). 2003. The E-business handbook: The 2003 review of innovation at work in South African companies. $4^{\text {th }}$ Edition. Cape Town: Trialogue. 